\title{
Poorly Documented Association of PPI Usage with Osteoporosis: A Review
}

\author{
Zubair Ahmed* \\ Department of Community Medicine, Pakistan
}

*Corresponding author: Zubair Ahmed, FMH College of Medicine and Dentistry, Department of Community medicine, Lahore Main Canal Road Gillani Mohala street, Jaranwala, District Faisalabad, Pakistan.

To Cite This Article: Zubair Ahmed. Poorly Documented Association of PPI Usage with Osteoporosis: A Review. Am J Biomed Sci \& Res. 2019 3(1). AJBSR.MS.ID.000634. DOI: 10.34297/AJBSR.2019.03.000634

Received: May 17, 2019 | Published: May 21, 2019

\begin{abstract}
Proton pump inhibitors are an effective class of pharmacotherapeutic drugs used to reduce stomach acid secretion and drug of choice for GERD, published literature suggested relatively less side effects and high efficacy but some recent studies have suggested that chronic PPIs usage leads to negative calcium balance with decreased absorption due to acid suppression and parathyroid hyperplasia as the plausible explanation for this less documented side effect of this widely used class of drugs increasing the risk for osteoporosis and resultant bone fractures. But no groundbreaking research has been published on interaction between PPIs and calcium homeostasis and must be taken up by researchers since the sheer prevalence of using PPIs further enhances the importance to completely understand the underlying mechanism and complex biochemical interactions and possible comorbidities with chronic usage.
\end{abstract}

\section{Introduction \& Background}

Proton pump inhibitors have been extensively used by the general population since their introduction in late 1980s because of their high efficacy in acid related conditions and relatively less observed side effects [1]. Proton pump inhibitors are a group of drugs which reduce stomach acid secretion and are most effective class of acid secretion inhibitors [2]. PPIs are used as drug of choice in gastro esophageal reflux (GERD) in which lower esophageal sphincter is affected resulting in the backflow of acidic secretions of stomach causing heart burn and indigestion. Despite h2 receptor blockers being antacids too PPIs are preferred in the light of better clinical outcomes [3].Millions of American adults take PPIs to treat or prevent gastrointestinal conditions [4]. Indeed, PPIs rank second only to statins in drug sales with postmenopausal women accounting for over half of long-term users [5]. Recent literature has hinted at association between PPIs usage and increased risk of osteoporosis especially with chronic PPIs usage affecting calcium homeostasis although not clearly understood and less researched.

\section{Review}

Recently documented side effect of previously safe considered PPIs includes osteoporosis that has been indicated in literature to be caused by several mechanisms:

a. including inhibition of osteoclastic proton pumps causing reduction in bone resorption, b. long term suppression of stomach acid could potentially lead to decreased calcium uptake from intestines since the gastric acid ionizes calcium to increase it absorption.

Other possible factors include secondary hypergastrinemia causing increased resorption of bone by inducing parathyroid gland hyperplasia [6]. PPIs have been identified as an independent risk factor in osteoporotic fractures in literature by causing hypochlorhydria reduced absorption and negative calcium balance therefore disrupting the normal calcium balance and leading to brittle bone with increased risk of fracture $[7,8]$. Literature has identified reduced stomach acid secretion as risk factor or calcium absorption along with other minerals [9].

A single study conducted on a small study group concluded a 28 percent increase in serum PTH level after 8 weeks of omeprazole therapy from baseline levels along with increases in several markers of bone turnover including serum osteocalcin, alkaline phosphatase and tartrate resistant acid phosphate. However, urinary excretion of hydroxyproline and calcium decreased [10]. One study showed a considerable increased risk of bone fracture with 7 years or more therapy with PPIs [11]. In a large prospective cohort study, an association was found between PPIs usage and osteoporotic fracture which poses a serious problem since these fractures are related with high morbidity and mortality [12]. Another population 
study found significant association between ppis and fracture in young adults with evidence of dose response effects [13].

\section{Conclusions}

This association between PPIs and osteoporosis has been comparatively less reported in literature and can have serious implications on health of patients but lacks any definitive randomized controlled trials to explain this poorly researched phenomenon and must be further explored. Patients must be informed of this less reported side effect and PPIs should be carefully prescribed and lower dosage be prescribed when deemed possible.

\section{References}

1. Strand DS, Kim D, Peura DA (2017) 25 years of proton pump inhibitors: a comprehensive review. Gut and liver 11(1): 27-37.

2. Sachs G, Shin JM, Howden CW (2006) The clinical pharmacology of proton pump inhibitors. 2: 2-8.

3. Ng FH, Wong SY, Lam KF, Chu WM, Chan P, et al. (2010) Famotidine is inferior to pantoprazole in preventing recurrence of aspirin-related peptic ulcers or erosions. 138(1): 82-88

4. Hansen KE, Jones AN, Lindstrom MJ, Davis LA, Ziegler TE, et al. (2010) Do proton pump inhibitors decrease calcium absorption? J Bone Miner Res 25(12): 2786-2795.

5. Raghunath AS, O'Morain C, McLoughlin RC (2005) Review article: the long-term use of proton-pump inhibitors. Aliment Pharmacol Ther 22 Suppl 1: 55-63.
6. Yang YX (2008) Proton pump inhibitor therapy and osteoporosis. Curr Drug Saf 3(3): 204-209.

7. Jacobson BC, Ferris TG, Shea TL, Mahlis EM, Lee TH, et al. (2003) Who is using chronic acid suppression therapy and why? Am J Gastroenterol 98(1): 51-58.

8. Elaine WY, Blackwell T, Ensrud KE, Orwoll E, Bauer DC, et al. (2008) Acid-suppressive medications and risk of bone loss and fracture in older adults. Calcif Tissue Int 83(4): 251-259.

9. Yang YX (2012) Chronic proton pump inhibitor therapy and calcium metabolism. Curr Gastroenterol Rep 14(6): 473-479.

10. Mizunashi K, Furukawa Y, Katano K, Abe K (1993) Effect of omeprazole, an inhibitor of $\mathrm{H}+, \mathrm{K}+-\mathrm{ATPa} e$, on bone resorption in humans. Calcif Tissue Int 53(1): 21-25.

11. Targownik LE, Lix LM, Metge CJ, Leung S, Leslie WD, et al. (2008) Use of proton pump inhibitors and risk of osteoporosis-related fractures. Cmaj 179(4): 319-326.

12. Freedberg DE, Haynes K, Denburg MR, Abrams JA, Yang YX, et al. (2015) Use of proton pump inhibitors is associated with fractures in young adults: a population-based study. Osteoporos Int 26(10): 2501-2507.

13. Targownik LE, Leslie WD, Davison KS, Kaiser SM, Kovacs CS, et al. (2012) The relationship between proton pump inhibitor use and longitudinal change in bone mineral density: a population-based from the Canadian Multicentre Osteoporosis Study (CaMos). The Am J Gastroenterol 107(6): 1361-1369. 